\title{
Multi-Objective Faculty Course Assignment Problem with Result and Feedback Based Uncertain Preferences
}

\author{
Sunil B. Bhoi \\ Department of Applied Mathematics and Humanities, \\ Sardar Vallabhbhai National Institute of Technology, Surat, Gujarat, India. \\ Corresponding author: d18ma001@amhd.svnit.ac.in \\ Jayesh M. Dhodiya \\ Department of Applied Mathematics and Humanities, \\ Sardar Vallabhbhai National Institute of Technology, Surat, Gujarat, India. \\ E-mail: jdhodiya@yahoo.com
}

(Received on January 21, 2021; Accepted on May 17, 2021)

\begin{abstract}
In this paper, a multi-objective faculty course allocation problem with result analysis and feedback analysis based on uncertain preferences mathematical model is presented. To deal with an uncertain model, three different ranking criteria are being used to develop: a) Expected value, b) Optimistic value, c) Dependent optimistic value criterion. These mathematical models are transformed into their corresponding deterministic forms using the basic concepts of uncertainty theory. The deterministic model of DOCM consists of fractional objectives which are converted into their linear form using Charnes and Cooper's transformation. These deterministic formulations MOFCAP are converted into a single objective problem by using the fuzzy programming technique with linear and exponential membership functions. Further, the single objective problem for all the defined models is solved in the Lingo 18.0 software to derive the Pareto-optimal solution. The sensitivity of the models is also performed to examine the variation in the objective function due to the variation in parameters. Finally, a numerical example is given to exhibit the application and algorithm of the models.
\end{abstract}

Keywords- University course scheduling, 0-1 integer programming, Uncertainty theory, Fractional programming, Fuzzy programming approach.

\section{Introduction}

Faculty course allocation involves the allocation of time slots and resources to teachers of universities or colleges under few hard and soft constraints. Generally, such a problem can be solved manually by the administrator of the University or college. This task becomes very complicated if resources, time slots, faculties, and constraints are large. Indeed, the utilization of optimization techniques to generate timetables plays a vital role as these techniques always provide better schedules with mathematical support, in which it provides proper utilization of resources, the satisfaction of faculties and students are taken into it. Apart from its practical importance, the scheduling problem is NP-Hard (Abdelhalim and El Khayat, 2016). Many researchers from artificial intelligence and operational research fields are attracted to the University scheduling problem. A study on it was initiated by Csima and Gotlieb (1964). Thereafter, different kinds of approaches have been developed to deal with these problems. Metaheuristics methods are been used in many of these approaches and achieved remarkable results in a short time like simulated annealing (Bai et al., 2006; Gunawan et al., 2012), Tabu search (Hertz, 1991; Costa, 1994), hybrid harmony search (Al-Betar et al., 2012) evolutionary algorithm (Najdpour and Feizi-Derakhshi, 2010), genetic algorithm, etc. but these approaches not guarantees about optimality or optimality gaps. In such cases, exact approaches play a vital role such as mathematical programming and 
constraint programming. Schniederjans and Kim (1987) has reported preferences based faculty course allocation model and found result by goal programming. (Badri, 1996; Badri et al., 1998) have generalized this model in two phases and later on combined two phases. Daskalaki and Birbas (2005) presented a two-stage relaxation procedure that solves efficiently the integer programming formulation of a university scheduling problem. Bakır and Aksop (2008) developed binary integer programming based model for the department of Statistics at Gazi University, Turkey. Bhoi and Dhodiya (2020) have presented a mathematical model of multi-objective faculty course timeslot assignment problem with feedback and result-based real preferences in two stages. Feedback and result are very important to know the preferences from student's priorities. But some time no history of new faculties or probably faculty may take particular subject after few semesters. Preferences based on result and feedback analysis which may vary faculty to faculty, semester to semester, which can be handled with uncertainty theory and mostly due to inadequate information these parameters are uncertain. Feedback and result analysis based preferences are tackled in literature with real and fuzzy numbers. But, uncertain preferences based on feedback and result analysis are not been incorporated in University scheduling problem. Hence, uncertain preferences are addressed in this work. Liu (2007) introduced uncertainty theory to deal with the degree of belief and thereafter it has been improved by Liu (2009). Liu and Liu (2009) introduced the theory of uncertain programming and in 2015, developed uncertain multiobjective programming (Liu and Chen, 2015).

We have presented an uncertain model of faculty course assignments with uncertain preferences based on the result and feedback analysis. To deal with an uncertain model, three different ranking criteria are being used to develop: 1) Expected value, 2) Optimistic value, 3) Dependent optimistic value criterion model. Using uncertainty theory, these models are converted into deterministic models. These deterministic models are multiobjective, which are converted into a single objective model using the fuzzy programming technique (Zimmermann, 1978) and optimal solutions achieved using LINGO18.0 software.

This paper is arranged as Section 2 involves basic terms, example, and theorems on uncertainty theory, section 3 presents a formulation of the uncertain model and its deterministic models using three ranking criteria, section 4 presents fuzzy programming approach, section 5 presents a numerical example, section 6 shows results and discussion and in the last section, the conclusion is presented.

\section{Preliminaries}

Following basic terms and concepts are introduced for uncertainty theory and programming:

\section{Definition 1}

Suppose $\Pi$ be any non-empty set and $\mathfrak{R}$ be a $\sigma$-algebra over $\Pi$. Each element $\Omega \in \mathfrak{R}$ is called an event (Liu and Liu, 2009). The uncertain measure $\mathfrak{I}$ is a function from $\mathfrak{R}$ to [0;1] such that it satisfies the following properties:

1. (Normality) $\mathfrak{I}\{\Pi\}=1$ for any universal set $\Pi$.

2. (Self Duality) $\mathfrak{I}\{\Omega\}+\mathfrak{I}\left\{\Omega^{c}\right\}=1$ for any event $\Omega$.

3. (Subadditivity) For every countable sequence of events $\Omega_{i}$, we have $\mathfrak{I}\left\{\bigcup_{i=1}^{n} \Omega_{i}\right\} \leq \sum_{i=1}^{n} \mathfrak{I}\left\{\Omega_{i}\right\}$. 
The triplet $(\Omega, \mathfrak{R}, \mathfrak{I})$ is called an uncertainty space. However, the product uncertain measure is defined by product property:

4. (Product Measure) Let $\left(\Omega_{k}, \mathfrak{R}_{k}, \mathfrak{I}_{k}\right)$ be uncertainty space for $\mathrm{k}=1,2, \ldots$ The product uncertain measure $\mathfrak{I}$ satisfying $\mathfrak{I}\left\{\bigcup_{i=1}^{n} \Omega_{i}\right\}=\hat{i=1}_{\wedge}^{n} \mathfrak{I}\left\{\Omega_{i}\right\}$.

\section{Definition 2}

Let a measurable function from an uncertainty space $(\Omega, \mathfrak{R}, \mathfrak{I})$ to any Borel set $\mathrm{B}$ of real numbers is an uncertain variable, the set $\{\beta \in B\}=\{\pi \in \Pi \mid \beta(\pi) \in B\}$ is an event (Liu, 2007).

\section{Definition 3}

The uncertainty distribution $\psi: R \rightarrow[0,1]$ of an uncertain variable $\beta$ is defined by $\psi(x)=\mathfrak{I}(\beta \leq x)$ any real $\mathrm{x}(\mathrm{Liu}, 2007)$.

\section{Definition 4}

Let $\beta$ be an uncertain variable with uncertainty distribution (Liu, 2007).

$$
\psi(x)=\left\{\begin{array}{l}
0, \text { if } x \leq p, \\
\frac{x-p}{2(q-p)}, \text { if } p \leq x \leq q, \\
\frac{x+r-2 q}{2(r-q)}, \text { if } q \leq x \leq r, \\
1, \text { if } x \geq r .
\end{array}\right.
$$

is called zigzag uncertain variable denoted by $\mathrm{T}(p, q, r) ; p, q, r \in R$ and $p<q<r$. Zigzag uncertainty distribution shown in Figure 1.

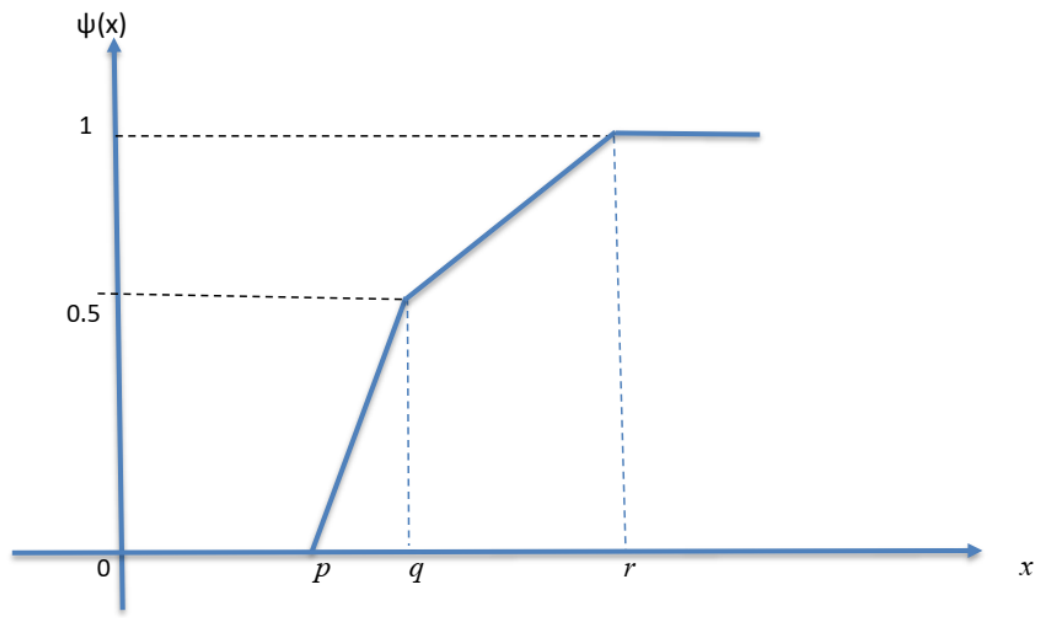

Figure 1. Zigzag uncertainty distribution. 


\section{Definition 5}

Suppose $\mathrm{T}(p, q, r)$ be a zigzag uncertain variable with uncertainty distribution $\psi$. Then the inverse uncertainty distribution function denoted by $\psi^{-1}$ of $\mathrm{T}(p, q, r)$ is given by Equation (2) (Liu, 2007). Also inverse uncertainty distribution shown in Figure 2.

$\psi^{-1}(\sigma)=\left\{\begin{array}{l}(1-2 \sigma) p+2 \sigma q, \text { if } \sigma<0.5, \\ (2-2 \sigma) q+(2 \sigma-1) r, \text { if } \sigma \geq 0.5\end{array}\right.$

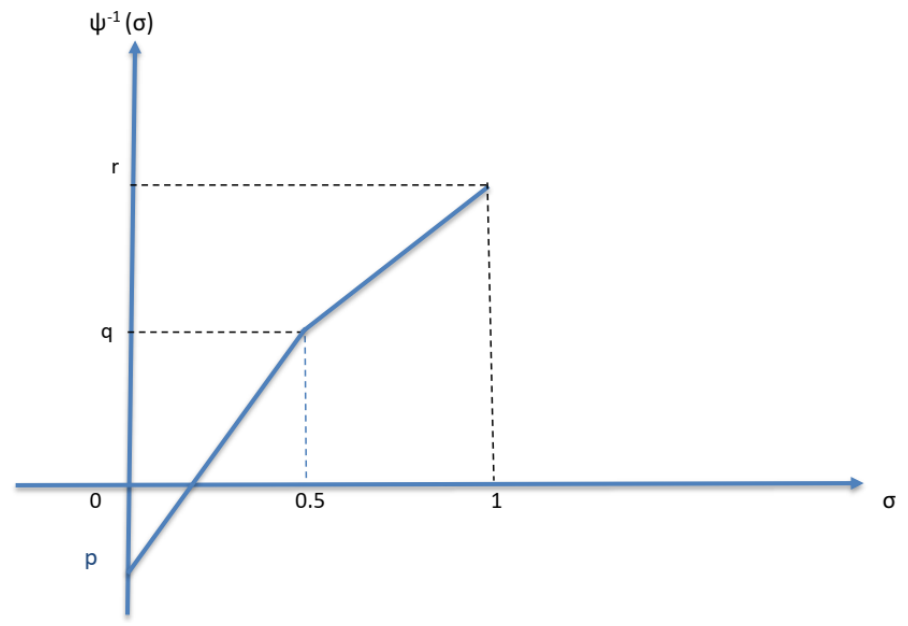

Figure 2. Inverse uncertainty distribution.

\section{Theorem 1}

Suppose $\psi_{1}, \psi_{2}, \ldots, \psi_{n}$ be an uncertainty distribution for $\beta_{1}, \beta_{2}, \ldots, \beta_{n}$ independent uncertain variables respectively. If $g\left(y_{1}, y_{2}, \ldots, y_{n}\right)$ is strictly non-decreasing concerning $y_{1}, y_{2}, \ldots ., y_{m}$ and strictly nonincreasing concerning $y_{m+1}, y_{m+2}, \ldots, y_{n}$ then $\beta=g\left(\beta_{1}, \beta_{2}, \ldots, \beta_{n}\right)$ is an uncertain variable for which inverse uncertainty distribution is

$\psi^{-1}(\sigma)=g\left(\psi_{1}^{-1}(\sigma), \psi_{2}^{-1}(\sigma), \ldots, \psi_{m}^{-1}(\sigma), \psi_{m+1}^{-1}(1-\sigma), \psi_{m+2}^{-1}(1-\sigma), \ldots \ldots, \psi_{n}^{-1}(1-\sigma)\right)$

\section{Theorem 2}

Suppose $\psi$ be uncertainty distribution corresponding to uncertain variable $\beta$, then

$E(\beta)=\int_{0}^{1} \psi^{-1}(\sigma) d \sigma$, if it exists.

The expected value of a zigzag uncertain variable $\beta \sim \mathrm{T}(p, q, r)$ is defined as 
$E(\beta)=\frac{p+2 q+r}{4}$

\section{Theorem 3}

Suppose $\mathrm{u}$ and $\mathrm{v}$ be any real numbers, $E(u \beta+v \lambda)=u E(\beta)+v E(\lambda)$ where, $\beta$ and $\lambda$ are independent uncertain variables for which expected value exists finitely.

\section{Theorem 4}

Suppose $\psi_{1}, \psi_{2}, \ldots, \psi_{n}$ be an uncertainty distribution for $\beta_{1}, \beta_{2}, \ldots, \beta_{n}$ independent uncertain variables respectively. If $g: R^{n} \rightarrow R$ is a strictly monotone function, then the uncertain variable $\beta=g\left(\beta_{1}, \beta_{2}, \ldots, \beta_{n}\right)$ has an expected value.

$E(\beta)=\int_{0}^{1} g\left(\psi_{1}^{-1}(\sigma), \psi_{2}^{-1}(\sigma), \ldots, \psi_{n}^{-1}(\sigma)\right) d \sigma$, the expected value $E(\beta)$ should exist.

\section{Theorem 5}

Suppose $x_{1}, x_{2}, \ldots, x_{n}$ are non-negative decision variables and $\beta_{1}, \beta_{2}, \ldots, \beta_{n}$ are independently zigzag uncertain variables $\mathrm{T}\left(p_{1}, q_{1}, r_{1}\right), \mathrm{T}\left(p_{2}, q_{2}, r_{2}\right), \ldots . ., \mathrm{T}\left(p_{n}, q_{n}, r_{n}\right)$ respectively. When

$\bar{g} \in\left[\sum_{i=1}^{n} p_{i} x_{i}, \sum_{i=1}^{n} q_{i} x_{i}\right]$

we have $\mathfrak{J}\left(\sum_{i=1}^{n} \beta_{i} x_{i} \leq \bar{g}\right)=\frac{\bar{g}-\sum_{i=1}^{n} p_{i} x_{i}}{2\left(q_{i}-p_{i}\right) x_{i}}$

When $\bar{g} \in\left[\sum_{i=1}^{n} q_{i} x_{i}, \sum_{i=1}^{n} r_{i} x_{i}\right]$,

we have $\mathfrak{I}\left(\sum_{i=1}^{n} \beta_{i} x_{i} \leq \bar{g}\right)=\frac{\bar{g}+\sum_{i=1}^{n}\left(r_{i}-2 q_{i}\right) x_{i}}{2\left(r_{i}-q_{i}\right) x_{i}}$

else, the measure will be 0 if $\bar{g}$ is on the left-hand side (6) or 1 if $\bar{g}$ is on the right-hand side of (8).

\section{Theorem 6}

Suppose $\beta$ be an uncertain variable and $v \in[0,1]$. Then $\beta_{\text {sup }}(v)=\sup \{b \mid \mathfrak{I}\{\beta \geq b\} \geq v$ is called the $v$-optimistic value to $\beta$ and $\beta_{\text {inf }}(v)=\inf \{b \mid \mathfrak{J}\{\beta \leq b\} \geq v\}$ is called the $v$-pessimistic value to $\beta$. 


\section{Theorem 7}

Suppose $\beta$ be an uncertain variable with an uncertainty distribution $\psi$. Then their $v$-optimistic value and v-pessimistic values are

$\beta_{\text {sup }}(v)=\psi^{-1}(1-v), \beta_{\text {inf }}(v)=\psi^{-1}(v)$.

\section{Example 1}

The $v$-optimistic and $v$-pessimistic values for $\mathrm{T}(p, q, r)$ are given by

$$
\begin{aligned}
& \beta_{\text {sup }}=\left\{\begin{array}{l}
2 v q+(1-2 v) r, \text { if } v<0.5 \\
(2 v-1) p+(2-2 v) q, \text { if } v \geq 0.5 .
\end{array}\right. \\
& \beta_{\mathrm{inf}}=\left(\begin{array}{l}
(1-2 v) p+2 v q, \text { if } v<0.5 \\
(2-2 v) q+(2 v-1) r, \text { if } v \geq 0.5 .
\end{array}\right.
\end{aligned}
$$

\section{Theorem 8}

Suppose $\beta$ be an uncertain variable, and $\mu \in(0,1]$. Then we have

(a) $\beta_{\text {inf }}(\mu)$ are a nondecreasing and left-continuous function of $\mu$.

(b) $\beta_{\text {sup }}(\mu)$ are a nonincreasing and left-continuous function of $\mu$.

\section{Theorem 9}

Suppose $\beta_{1}, \beta_{2}, \ldots, \beta_{n}$ be independent uncertain variables with uncertainty distributions. If $g: R^{n} \rightarrow R$ is a continuous and strictly increasing function, then $\beta=g\left(\beta_{1}, \beta_{2}, \ldots, \beta_{n}\right)$ is an uncertain variable, and

$$
\beta_{\text {sup }}(\sigma)=g\left(\beta_{\text {sup }}(\sigma), \beta_{2 \text { sup }}(\sigma), \ldots, \beta_{n \text { sup }}(\sigma)\right), \beta_{\text {inf }}(\sigma)=g\left(\beta_{\text {linf }}(\sigma), \beta_{2 \text { inf }}(\sigma), \ldots, \beta_{\text {ninf }}(\sigma)\right)
$$

\section{Theorem 10}

Suppose $\beta$ be an uncertain variable, and $\mu \in(0,1]$. If $k \geq 0$, then

$(k \beta)_{\text {sup }}(\mu)=k \beta_{\text {sup }}(\mu),(k \beta)_{\text {inf }}(\mu)=k \beta_{\text {inf }}(\mu)$.

if $\mathrm{k}<0$, then $(k \beta)_{\text {sup }}(\mu)=k \beta_{\text {inf }}(\mu),(k \beta)_{\text {inf }}(\mu)=k \beta_{\text {sup }}(\mu)$

\section{Theorem 11}

Suppose that $\mathrm{x}$ and $\mathrm{y}$ are independent uncertain variables, and $\mu \in(0,1]$. Then we have

$$
(x+y)_{\text {sup }}(\mu)=x_{\text {sup }}(\mu)+y_{\text {sup }}(\mu),(x+y)_{\text {inf }}(\mu)=x_{\text {inf }}(\mu)+y_{\text {inf }}(\mu) .
$$

\section{Formulation of Uncertain Model}

Following parameters and decision variables are used to formulate multiobjective faculty course allocations with uncertain preferences based on feedback analysis and result from analysis. 


\section{Parameters}

$\mathrm{A}=\{1,2,3,4, \ldots, \mathrm{m}\}$ be set of all courses.

$\mathrm{A}=\bigcup_{i=1}^{n} A_{j}, \mathrm{~A}_{\mathrm{j}}$ is the set of subjects that teacher $\mathrm{j}$ can deliver.

$\mathrm{B}=\{1,2, \ldots, \mathrm{k}\}$ be the set of teachers.

$\mathrm{l}_{\mathrm{k}}$ and $\mathrm{u}_{\mathrm{k}}=$ minimum and maximum teaching loads for the teacher $\mathrm{k}$ weekly, respectively.

$\mathrm{t}_{\mathrm{ij}}=$ preference level of the course $\mathrm{i}$ by the teacher.

$\mathrm{a}_{\mathrm{ij}}=$ preference level for the allocation of the subject $\mathrm{i}$ to teacher $\mathrm{j}$ by an administrator.

$\xi_{\mathrm{ij}}=$ uncertain preference level based on feedback analysis for the allocation of the subject $\mathrm{i}$ to the teacher $\mathrm{j}$.

$\eta_{\mathrm{ij}}=$ uncertain preference level based on result analysis for the allocation of the subject $\mathrm{i}$ to the teacher $\mathrm{j}$.

\section{Decision Variable}

Let $\mathrm{x}_{\mathrm{ij}}$ denotes allotment, of course, $\mathrm{i}$ to teacher $\mathrm{j}$.

$x_{i j}=\left\{\begin{array}{l}1, \text { if subject } \mathrm{i} \text { allotted to teacher } \mathrm{j}, \\ 0, \text { otherwise. }\end{array}\right.$

\section{Constraints}

1. Each subject must be allotted to only one teacher:

$\sum_{j=1}^{n} x_{i j}=1, i=1,2, \ldots, m$.

2. Minimum and maximum teaching load in a week of the teacher should not violate i.e. allocation of teaching load should lie between the minimum and maximum weekly load.

$l_{k} \leq \sum x_{i j} \leq u_{k}, k=1,2, . ., n$

\section{Objectives}

$$
\begin{aligned}
& F_{j}(x)=\frac{\sum_{i=1}^{m} x_{i j} h_{i} t_{i j}}{\sum_{i=1}^{m} x_{i j} h_{i}}, j=1,2, \ldots, n . \\
& O_{1}(x)=\frac{\sum_{i=1}^{m} \sum_{j=1}^{n} x_{i j} h_{i} t_{i j}}{\sum_{i=1}^{m} \sum_{j=1}^{n} x_{i j} h_{i}},
\end{aligned}
$$


$O_{2}(x)=\sum_{i=1}^{m} \sum_{j=1}^{n} a_{i j} x_{i j}$

$O_{3}(x)=\sum_{j=1}^{n}\left(u_{j}-\sum_{i=1}^{m} x_{i j} h_{i}\right)$

$S_{1}(x, \xi)=\sum_{i=1}^{m} \sum_{j=1}^{n} \xi_{i j} x_{i j}$

$S_{2}(x, \eta)=\sum_{i=1}^{m} \sum_{j=1}^{n} \eta_{i j} x_{i j}$

Equation (19) represents the mean of preference level $\mathrm{L}_{\mathrm{j}}$ per hour taught. Equation (20) shows the mean of preferences of all teachers. Equation (21) denotes the sum of administrator preference level. Equation (22) represents the sum of dispersion from the maximum load of all teachers. Equation (23) represents uncertain preference based on the feedback analysis of teachers given by learners. Equation (24) uncertain preference based on the result analysis of teacher given by learners. The key problem in the uncertain model of faculty course allocation is the ranking of uncertain variables. To deal with an uncertain model, three different ranking criteria are utilized to develop: a) Expected value, b) Optimistic value, c) Dependent optimistic value criterion model.

\subsection{Expected Value Model}

Using expected values of uncertain variables expected value model is:

Minimize $\left[F_{j}(x), O_{1}(x), O_{2}(x), O_{3}(x), E\left(S_{1}(x, \xi), E\left(S_{2}(x, \eta)\right], \quad \mathrm{j}=1,2, \ldots \mathrm{m}\right.\right.$. Subject to constraints (17) and (18).

\subsection{Optimistic Value Model}

Using optimistic values of uncertain variables Optimistic value model is:

Minimize $\left[F_{j}(x), O_{1}(x), O_{2}(x), O_{3}(x),\left(S_{1}(x, \xi)_{\text {sup }}\left(\alpha_{t}\right),\left(S_{2}(x, \eta)_{\text {sup }}\left(\alpha_{t}\right)\right] \quad \mathrm{j}=1,2, \ldots \mathrm{m}\right.\right.$.

$\mathrm{t}=1,2, \ldots$. Subject to constraints (17) and (18).

\subsection{Dependent Optimistic Value Criterion Model}

Dependent Optimistic value model is:

Minimize $\left[F_{j}(x), O_{1}(x), O_{2}(x), O_{3}(x)\right]$.

Maximize $\left[\mathcal{M}\left\{\sum_{i=1}^{m} \sum_{j=1}^{n} \xi_{i j} x_{i j} \leq \bar{f}_{t}\right\}, \mathcal{M}\left\{\sum_{i=1}^{m} \sum_{j=1}^{n} \eta_{i j} x_{i j} \leq \bar{f}_{t}\right\}\right], t=1,2, \ldots, p$.

Subject to constraints (17) and (18).

\section{Methodology}

Zimmermann (1978) has introduced the fuzzy programming approach to the linear vector maximum/minimum problem. He has also proved that solutions obtained by the fuzzy programming approach are always efficient (optimal compromised solution /non-dominated solution). In this paper, we have formulated an Uncertain model, which has been reduced to 
deterministic models by three ranking criteria. These deterministic models are vector maximum models and required efficient solutions. Therefore, a fuzzy programming approach has been used. The fuzzy objective function is characterized by the membership function. Two types of membership functions i.e. linear and exponential are used to solve the model. As parameter $s$ in exponential changes, accordingly, distinct optimal compromise solutions are found with a distinct level of satisfaction. For course scheduling problems, different assignments are required. Using linear membership, we found the solutions for three models, which have been given in section 5 . But the assignment is only one. Using the exponential membership function, we found a variety of solutions as we change the shape parameter. Various assignments are found using the exponential membership function. Models with these membership functions provide distinct assignments.

\subsection{Working Procedure}

Steps to solve the proposed model are as follows:

(i) Read all the parameters related to the faculty course and formulate the mathematical model MOFCAP.

(ii) Find the positive ideal solution and negative ideal solution for each objective function.

(iii) Convert the crisp multiobjective of faculty course assignment into the single objective optimization problem by using linear membership and exponential membership function.

(iv) Solve a single objective optimization problem achieves in step 3 using the fuzzy membership function.

(v) If the solution is acceptable by a decision-maker, then stop otherwise change the value of $\mathrm{s}$ till the satisfactory result is achieved.

\subsection{Algorithm}

Input: Parameters: $\left(Z_{1}, Z_{2}, \ldots, Z_{k}, n\right)$

Output: To find the solution of MOFCAP

Solve MOFCAP $\left(z_{k} \downarrow, X \uparrow\right)$

begin

read: problem

while problem $=$ MOFCAP do

for $k=1$ to $n$ do

enter objectives $Z_{k}$

end

for $k=1$ to $n$ do

$z_{k}^{P I S}=\min \left(Z_{k}\right)$

Subject to the given constraints

end

for $k=1$ to $n$ do

$z_{k}^{\mathrm{NIS}}=\max \left(Z_{k}\right)$

Subject to the constraints

end

for $k=1$ to $n d o$

$\max \lambda$,

Subject to constraints $\left(u_{k}-f_{k}(x)\right) \geq \lambda\left(u_{k}-l_{k}\right)$ and given constraints 
end

and/or

for $k=1$ to $n$ do

$\max \lambda,\left(e^{-S \Psi_{k}(x)}-e^{-S}\right) \geq \lambda\left(1-e^{-S}\right)$,

where $\Psi_{k}(x) \leq \frac{f_{k}(x)-l_{k}}{u_{k}-l_{k}}$ and given constraints

end

\section{Numerical Illustration}

To test the strength and application of this proposed model, one hypothetical case has been completely studied and found its results using LINGO18.0 software. Assume that ABC technical institute offering various four-year undergraduate programs. We have taken one four-year program in which total allocation is to be done for 18 courses to 6 faculty members. In Table 1 maximum and minimum bounds are shown.

Table 1. Maximum and minimum courses limits.

\begin{tabular}{|l|c|c|c|c|c|c|}
\hline Teaching Load & Faculty1 & Faculty2 & Faculty3 & Faculty4 & Faculty5 & Faculty6 \\
\hline Minimum & 1 & 1 & 1 & 2 & 2 & 2 \\
\hline Maximum & 2 & 2 & 2 & 4 & 4 & 4 \\
\hline
\end{tabular}

In Table 2, faculty preferences are been collected and reflected. Four preferences are considered, 1 is the most desired one. As faculty 1 provided preferences $2,1,1,4,3,4$ for $3,5,11,13,16,17$ respectively. In Table 3, preferences for courses supplied by an administrator are shown. Result and feedback are important components teaching and learning process, but it is uncertain due to insufficient information. Uncertain preferences for faculties by considering the result and feedback data are shown in Table 4 and Table 5.

Table 2. Faculty preferences for courses.

\begin{tabular}{|c|c|c|c|c|c|c|}
\hline Courses & Fac1 & Fac2 & Fac3 & Fac4 & Fac5 & Fac6 \\
\hline 1 & & & & 4 & 1 & 2 \\
\hline 2 & & 2 & & & 3 & 1 \\
\hline 3 & 2 & & 1 & 4 & & 4 \\
\hline 4 & & 3 & & 1 & 2 & 3 \\
\hline 5 & 1 & & 2 & 3 & 1 & \\
\hline 6 & & 4 & & & 2 & 3 \\
\hline 7 & & & & 1 & 4 & \\
\hline 8 & & & 4 & & & 4 \\
\hline 9 & & 2 & & & 4 & \\
\hline 10 & & & & 2 & & 2 \\
\hline 11 & 1 & & & 3 & 4 & 4 \\
\hline 12 & & & 1 & 4 & 3 & \\
\hline 13 & 4 & & & 4 & & 1 \\
\hline 14 & & 3 & & & 4 & \\
\hline 15 & & & 2 & 3 & & 3 \\
\hline 16 & 3 & & 3 & & & 1 \\
\hline 17 & 4 & & & 1 & 3 & 1 \\
\hline 18 & & 1 & & 2 & 2 & \\
\hline & $<=2$ & $<=2$ & $<=2$ & $<=4$ & $<=4$ & $<=4$ \\
\hline
\end{tabular}


Bhoi \& Dhodiya: Multi-Objective Faculty Course Assignment Problem with Result and ...

Table 3. Administrator preferences for courses.

\begin{tabular}{|c|c|c|c|c|c|c|}
\hline Courses & Fac1 & Fac2 & Fac3 & Fac4 & Fac5 & Fac6 \\
\hline 1 & & & & 1 & 2 & 4 \\
\hline 2 & & 4 & & & 1 & 3 \\
\hline 3 & 1000 & & 3 & 2 & & 1000 \\
\hline 4 & & 2 & & 1000 & 4 & 1 \\
\hline 5 & 4 & & 4 & 1 & 2 & \\
\hline 6 & & 1000 & & & 1000 & 2 \\
\hline 7 & & & & 3 & 1 & \\
\hline 8 & & & 1000 & & & 1 \\
\hline 9 & & 1 & & & 1 & \\
\hline 10 & & & & 4 & & 3 \\
\hline 11 & 3 & & & 2 & 2 & 1 \\
\hline 12 & & & 2 & 3 & 4 & \\
\hline 13 & 1 & & & 2 & & 4 \\
\hline 14 & & 2 & & & 1000 & \\
\hline 15 & & & 1 & 1000 & & 1000 \\
\hline 16 & 1 & & 4 & & & 3 \\
\hline 17 & 2 & & & 4 & 1 & 3 \\
\hline 18 & & 4 & & 3 & 4 & \\
\hline
\end{tabular}

Table 4. Result based uncertain preferences.

\begin{tabular}{|c|c|c|c|c|c|c|}
\hline Courses & Fac1 & Fac2 & Fac3 & Fac4 & Fac5 & Fac6 \\
\hline 1 & & & & $(7,8,9)$ & $(1,2,4)$ & $(2,3,5)$ \\
\hline 2 & & $(1,3,4)$ & & & $(4,5,7)$ & $(1,2,3)$ \\
\hline 3 & $(2,4,5)$ & & $(2,4,5)$ & $(5,6,8)$ & & $(2,5,7)$ \\
\hline 4 & & $(2,5,6)$ & & $(1,2,3)$ & $(3,5,6)$ & $(3,4,6)$ \\
\hline 5 & $(5,7,9)$ & & $(1,3,4)$ & $(3,4,6)$ & $(1,2,3)$ & \\
\hline 6 & & $(3,5,6)$ & & & $(1,3,4)$ & $(2,4,5)$ \\
\hline 7 & & & & $(2,4,5)$ & $(2,3,4)$ & \\
\hline 8 & & & $(6,7,9)$ & & & $(4,7,8)$ \\
\hline 9 & & $(1,2,4)$ & & & $(1,4,5)$ & \\
\hline 10 & & & & $(3,5,6)$ & & $(1,3,4)$ \\
\hline 11 & $(3,4,6)$ & & & $(4,5,7)$ & $(5,7,8)$ & $(4,5,7)$ \\
\hline 12 & & & $(2,4,5)$ & $(7,8,9)$ & $(2,3,5)$ & \\
\hline 13 & $(1,3,4)$ & & & $(6,8,9)$ & & $(1,2,3)$ \\
\hline 14 & & $(5,6,8)$ & & & $(1,2,4)$ & \\
\hline 15 & & & $(2,4,6)$ & $(4,5,7)$ & & $(4,5,7)$ \\
\hline 16 & $(4,5,7)$ & & $(3,5,7)$ & & & $(2,3,5)$ \\
\hline 17 & $(2,4,6)$ & & & $(2,3,4)$ & $(2,3,5)$ & $(2,4,5)$ \\
\hline 18 & & $(3,4,5)$ & & $(1,2,4)$ & $(1,2,4)$ & \\
\hline
\end{tabular}

Table 5. Feedback based uncertain preferences.

\begin{tabular}{|c|c|c|c|c|c|c|}
\hline Courses & Fac1 & Fac2 & Fac3 & Fac4 & Fac5 & Fac6 \\
\hline 1 & & & & $(1,3,5)$ & $(1,2,4)$ & $(5,6,8)$ \\
\hline 2 & & $(2,5,6)$ & & & $(4,6,7)$ & $(2,4,5)$ \\
\hline 3 & $(3,5,7)$ & & $(2,3,4)$ & $(2,4,6)$ & & $(5,7,9)$ \\
\hline 4 & & $(5,6,7)$ & & $(1,3,4)$ & $(3,5,7)$ & $(2,4,6)$ \\
\hline 5 & $(1,2,3)$ & & $(2,5,6)$ & $(4,5,7)$ & $(1,2,3)$ & \\
\hline 6 & & $(6,7,9)$ & & & $(4,5,6)$ & $(1,3,5)$ \\
\hline 7 & & & & $(2,3,4)$ & $(5,7,8)$ & \\
\hline 8 & & & $(6,7,9)$ & & & $(4,6,7)$ \\
\hline 9 & & $(3,4,6)$ & & & $(4,6,8)$ & \\
\hline 10 & & & & $(3,4,6)$ & & $(3,5,7)$ \\
\hline 11 & $(1,2,4)$ & & & $(5,6,7)$ & $(1,3,5)$ & $(2,3,5)$ \\
\hline
\end{tabular}


Table 5 continued...

\begin{tabular}{|l|c|c|c|c|c|c|}
\hline 12 & & & $(1,2,3)$ & $(7,8,9)$ & $(2,3,4)$ & \\
\hline 13 & $(7,8,9)$ & & & $(5,7,9)$ & & $(1,3,5)$ \\
\hline 14 & & $(3,5,7)$ & & & $(5,7,9)$ & \\
\hline 15 & & & $(2,4,5)$ & $(2,3,5)$ & & $(5,7,9)$ \\
\hline 16 & $(3,4,6)$ & & $(2,4,5)$ & & & $(1,2,4)$ \\
\hline 17 & $(6,7,9)$ & & & $(1,2,4)$ & $(3,4,5)$ & $(1,2,4)$ \\
\hline 18 & & $(1,2,3)$ & & $(3,5,7)$ & $(2,4,5)$ & \\
\hline
\end{tabular}

\section{Results and Discussion}

Utilizing data in section 4, expected value model, optimistic value model, and dependent optimistic value models are formulated and solved by fuzzy programming technique. The objective values and courses assigned using linear and non-linear membership functions for the expected value model are shown in Table 6. Likewise, solutions of the optimistic value model and dependent optimistic value model are shown in Table 7, Table 8, and Table 9.

Objective values level of satisfaction, linear and non-linear membership functions for uncertain preferences of expected value model are shown graphically in Figure 3 to Figure 6 respectively.

Table 6. Objective values and courses assigned using expected value.

\begin{tabular}{|c|c|c|c|c|}
\hline Objective values & Linear Membership function & $S=0.00001$ & $S=0.00005$ & $S=0.000005$ \\
\hline$\lambda$ & 0.6657247 & 0.7336158 & 0.6657192 & 0.7421434 \\
\hline F1 & 1.9375 & 1.925 & 1.9375 & 2.05 \\
\hline $\mathrm{F} 2$ & 2 & 1.3333 & 2 & 2 \\
\hline F3 & 2 & 2 & 2 & 1.4 \\
\hline F4 & 1.4999 & 1.5 & 1.5 & 1.5 \\
\hline F5 & 1.8 & 1.6875 & 1.8 & 2.25 \\
\hline F6 & 2.1538 & 2.384615 & 2.153846 & 2.4 \\
\hline F7 & 1.8125 & 1.5 & 1.8125 & 2 \\
\hline F8 & 2038 & 2042 & 2038 & 1043 \\
\hline F9 & 3 & 3 & 3 & 3 \\
\hline F10 & 67.25 & 69.75 & 67.25 & 67.75 \\
\hline F11 & 64 & 67.75 & 64 & 63.75 \\
\hline \multicolumn{5}{|c|}{ Courses assigned to faculties. } \\
\hline Fac-I & 11,16 & 03,11 & 11,16 & 11,16 \\
\hline Fac-II & 14,18 & 14,18 & 14,18 & 09,18 \\
\hline Fac-III & 12,15 & 12,15 & 12,15 & 12,15 \\
\hline Fac-IV & $03,04,07,17$ & $05,07,10,17$ & $03,04,07,17$ & $03,07,10,17$ \\
\hline Fac-V & $1,06,09,11$ & $01,04,06,09$ & $01,05,06,09$ & $01,04,05,14$ \\
\hline Fac-VI & $2,8,10,13$ & $02,08,13,16$ & $02,06,08,13$ & $02,06,08,13$ \\
\hline
\end{tabular}

For the linear membership function, the satisfaction level is $\lambda=0.66577247$. Faculty-I assigned courses 11 and 16. Faculty has provided first for 11 and third for 16 and admin provided third for 11 and first 16. When we use the non-linear membership function for shape parameters $=0.00001$, course 3 assigned even admin not willing to assign it. 


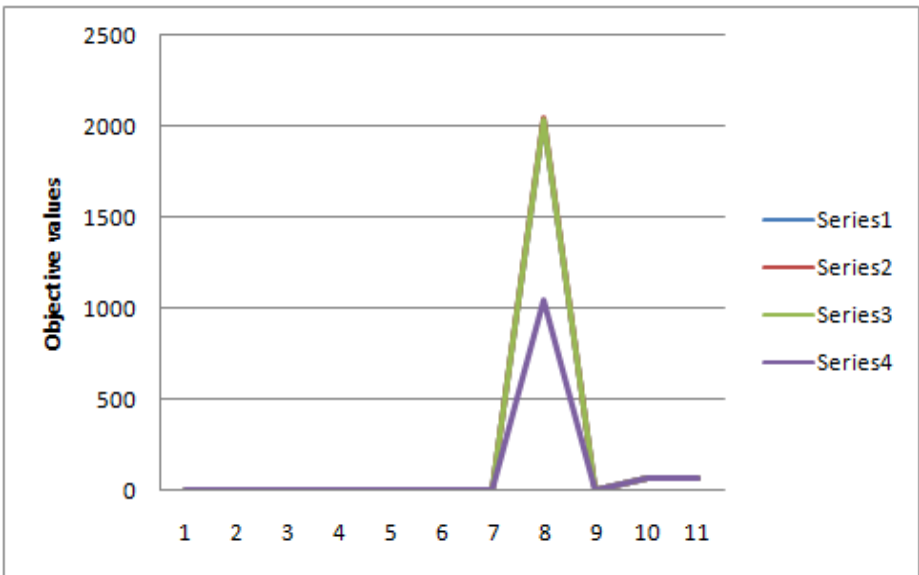

Figure 3. Objective values.

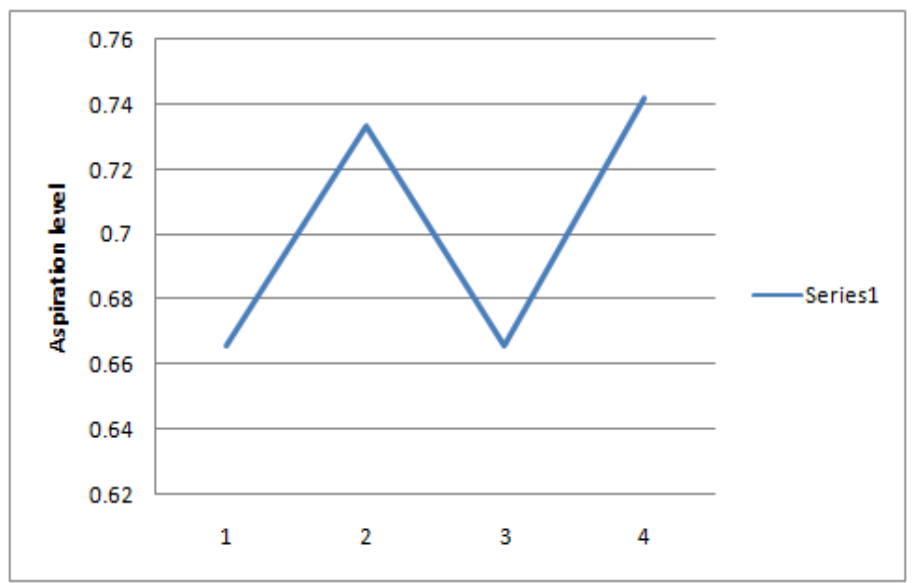

Figure 4. Level of satisfaction.
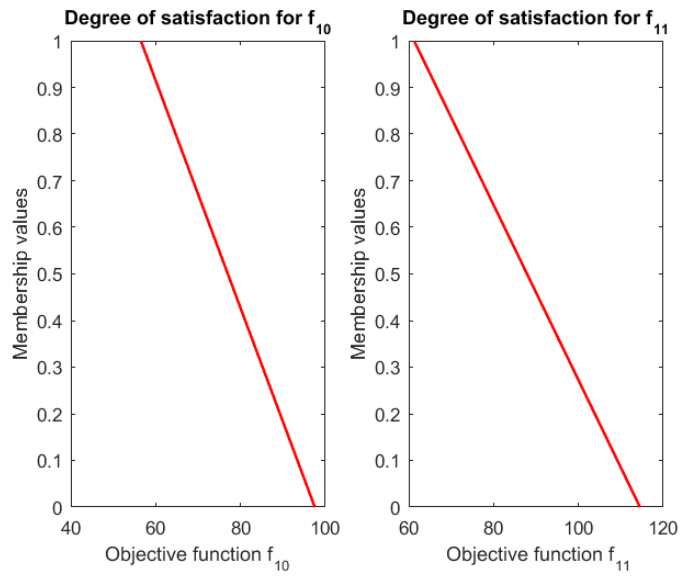

Figure 5. Linear membership function. 

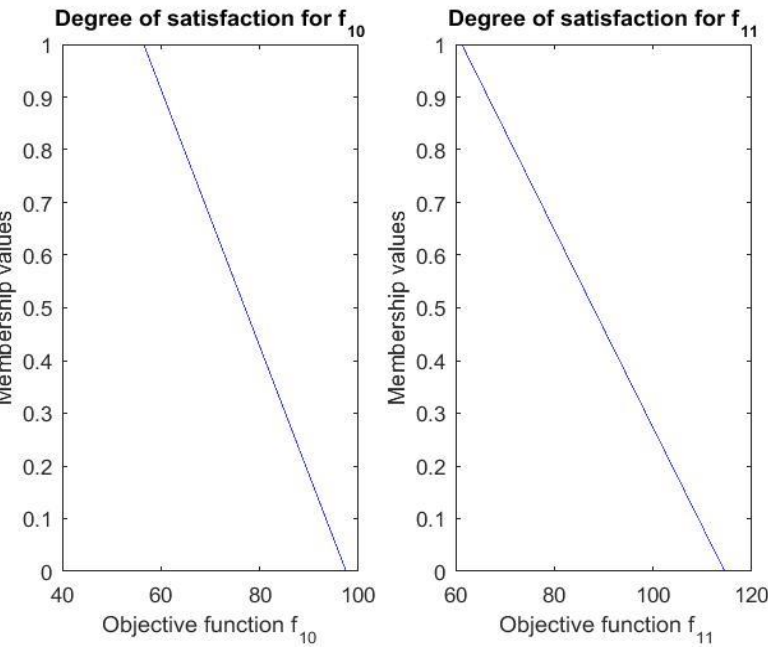

Figure 6. Exponential membership function.

Table 7. Objective values for linear and non-linear membership functions with $\alpha=0.9$.

\begin{tabular}{|c|c|c|c|c|}
\hline $\begin{array}{c}\text { Objective } \\
\text { values }\end{array}$ & $\begin{array}{l}\text { Linear } \\
\text { Membership } \\
\text { function }\end{array}$ & $\begin{array}{c}\mathrm{S} 1=\mathrm{s} 2=\mathrm{s} 3=\mathrm{s} 4= \\
\mathrm{s} 5= \\
\mathrm{s} 6=\mathrm{s} 7=\mathrm{s} 8= \\
\mathrm{s} 9=\mathrm{s} 10=\mathrm{s} 11=0.00001\end{array}$ & $\begin{array}{c}\mathrm{S} 1=0.000009=\mathrm{s} 2= \\
\mathrm{s} 3=\mathrm{s} 4=\mathrm{s} 5= \\
\mathrm{s} 6, \mathrm{~s} 7=0.000005= \\
\mathrm{s} 8=\mathrm{s} 9, \mathrm{~s} 10=0.000001=\mathrm{s} 11\end{array}$ & $\begin{array}{c}\mathrm{S} 1=00005=\mathrm{s} 2=\mathrm{s} 3=\mathrm{s} 4 \\
, \mathrm{~s} 5=0.00007 \\
\mathrm{~s}=0.00007=\mathrm{s} 7 \\
\mathrm{~s} 8=0.00009=\mathrm{s} 9, \mathrm{~s} 10=0.00006=\mathrm{s} 11\end{array}$ \\
\hline$\lambda$ & 0.6643949 & 0.6691637 & 0.66666 & 0.666661 \\
\hline F1 & 2.0625 & 1.95 & 2.0875 & 1.975 \\
\hline $\mathrm{F} 2$ & 1 & 1.3333 & 1.3333 & 2 \\
\hline F3 & 2 & 2 & 2 & 2 \\
\hline $\mathrm{F} 4$ & 1.8 & 2 & 2 & 2 \\
\hline F5 & 2 & 1.3333 & 1.615385 & 1.846154 \\
\hline F6 & 1.5 & 1.5 & 2 & 1.33333 \\
\hline F7 & 2 & 1.8125 & 2 & 2 \\
\hline $\mathrm{F} 8$ & 2046 & 2043 & 2040 & 2042 \\
\hline F9 & 3 & 3 & 3 & 3 \\
\hline F10 & 45.4 & 45.2 & 45.2 & 47.8 \\
\hline F11 & 42.2 & 43.4 & 41.6 & 45 \\
\hline \multicolumn{5}{|c|}{ Courses assigned to faculties. } \\
\hline Fac-I & 11 & 03,11 & 03,11 & 11,16 \\
\hline Fac-II & $02,09,14,18$ & $09,14,18$ & $09,14,18$ & $09,14,18$ \\
\hline Fac-III & $03,12,16$ & $12,15,16$ & $12,15,16$ & $08,12,15$ \\
\hline Fac-IV & $07,15,17$ & 07,17 & $04,10,17$ & $07,10,17$ \\
\hline Fac-V & $01,04,05,06$ & $01,04,05,06$ & $01,05,07$ & $01,04,05$ \\
\hline Fac-VI & $08,10,13$ & $02,08,10,13$ & $02,06,08,13$ & $02,03,06,13$ \\
\hline
\end{tabular}

For $\alpha=0.9$, the optimistic value model assigned faculty 1 course 11 , and the exponential membership function assigned other courses to faculty 1 . For $\alpha=0.1$, the optimistic model assigned courses 11 and 16 to faculty 1 .

Objective values, level of satisfaction, linear and non-linear membership functions for uncertain preferences of optimistic value model for $\alpha=0.9$ are shown graphically in Figure 7 to Figure 10 respectively. Similarly for $\alpha=0.1$, it is shown from Figure 11 to Figure 16 respectively. 


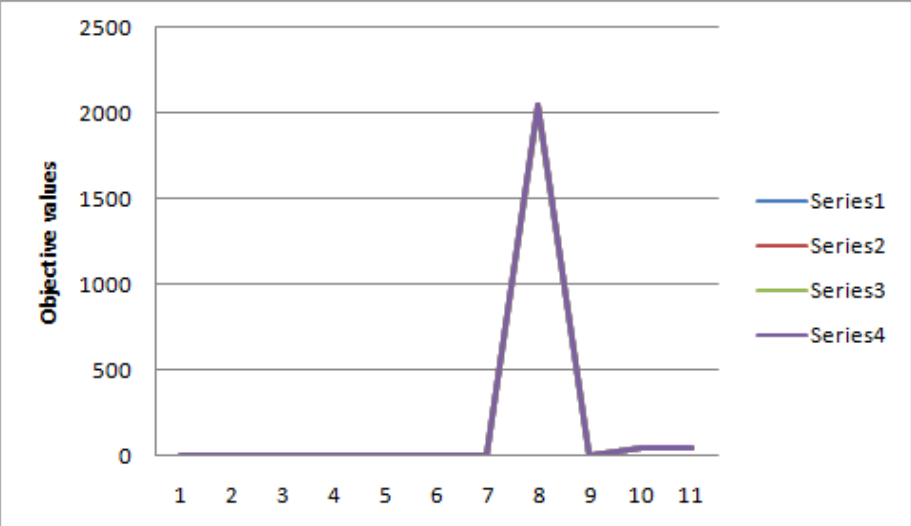

Figure 7. Objective values.

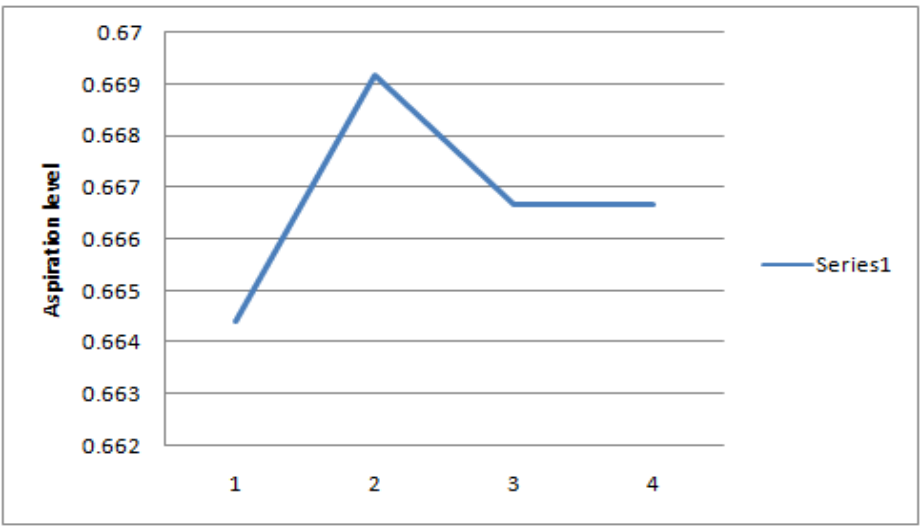

Figure 8. Level of satisfaction.
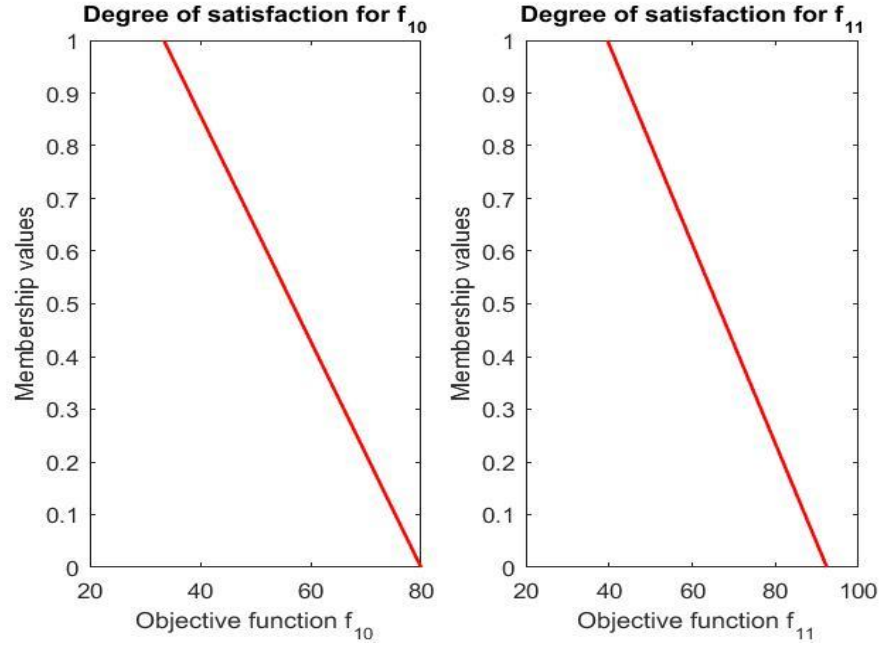

Figure 9. Linear membership function. 

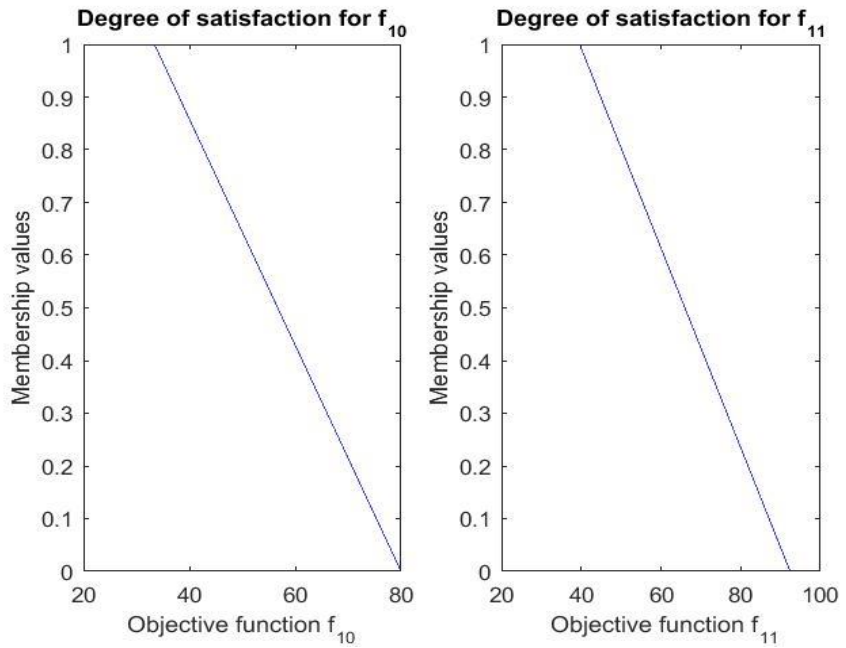

Figure 10. Nonlinear membership function.

Table 8. Objective values for linear and non-linear membership functions with $\alpha=0.1$.

\begin{tabular}{|c|c|c|c|c|}
\hline $\begin{array}{l}\text { Objective } \\
\text { values }\end{array}$ & $\begin{array}{l}\text { Linear } \\
\text { Membership } \\
\text { function }\end{array}$ & $\begin{array}{c}\mathrm{S} 1=00005=\mathrm{s} 2=\mathrm{s} 3 \\
=\mathrm{s} 4, \mathrm{~s} 5=0.0007=\mathrm{s} 6= \\
\mathrm{s} 7, \mathrm{~s} 8=0.0009, \mathrm{~s} 9= \\
\mathrm{s} 10=\mathrm{s} 11=0.0006\end{array}$ & $\begin{array}{c}\text { S1 }=0.00003, s 2=0.0003 \\
\text { s3 }=0.0009, s 4=0.00008 \\
\text { s5 }=0.00007, s 6=0.0000 \\
\text { s7 }=0.000005, s 8=0.00004 \\
\text { s9 }=\mathbf{s 1 0}=0.00003, s 11=0.0002\end{array}$ & $\begin{array}{c}\text { S1=00002,s2 }=0.0001, \\
\text { s3=0.0009,s4=0.00008, } \\
\text { s5 }=0.0007, \mathbf{s 6}=0.0006, \\
\text { s7 }=0.0005, \mathrm{~s} 8=0.0004 \\
=\mathrm{s} 9=0.003,, \mathbf{s} 10=0.0003, \\
\text { s11 }=0.0002\end{array}$ \\
\hline$\lambda$ & 0.6666667 & 0.666661 & 0.666663 & 0.6666567 \\
\hline F1 & 1.825 & 2.0125 & 1.8625 & 1.825 \\
\hline $\mathrm{F} 2$ & 2 & 1 & 2 & 2 \\
\hline F3 & 2 & 2 & 2 & 2 \\
\hline $\mathrm{F} 4$ & 1.4 & 1.4 & 1.4 & 1.4 \\
\hline F5 & 1.6875 & 1.6875 & 1.846154 & 1.6875 \\
\hline F6 & 1 & 1.5 & 1.3333 & 1 \\
\hline F7 & 2 & 1.8333 & 2 & 2 \\
\hline F8 & 1042 & 1048 & 1046 & 1042 \\
\hline F9 & 3 & 3 & 3 & 3 \\
\hline F10 & 85.2 & 90 & 88.2 & 85.2 \\
\hline F11 & 79.6 & 85.2 & 82.4 & 79.6 \\
\hline \multicolumn{5}{|c|}{ Courses assigned to faculties. } \\
\hline Fac-I & 11,16 & 11 & 11,16 & 11,16 \\
\hline Fac-II & $09,14,18$ & $02,09,14,18$ & $09,14,18$ & $09,14,18$ \\
\hline Fac-III & $03,12,15$ & $03,12,15$ & $03,12,15$ & $03,12,15$ \\
\hline Fac-IV & $04,07,10,17$ & $05,07,10,17$ & $07,10,17$ & $04,07,10,17$ \\
\hline Fac-V & 01,05 & 01,04 & $01,04,05$ & 01,05 \\
\hline Fac-VI & $02,06,08,13$ & $06,08,13,16$ & $02,06,08,13$ & $02,06,08,13$ \\
\hline
\end{tabular}




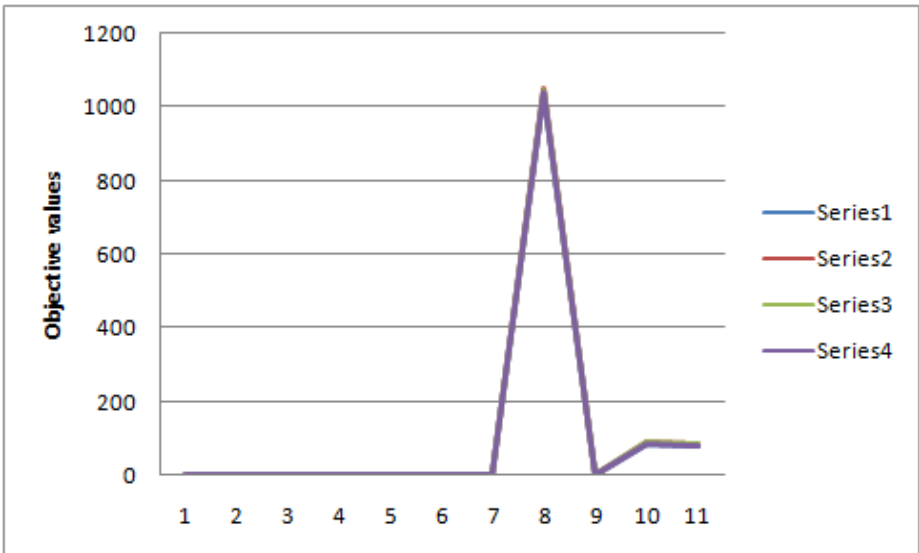

Figure 11. Objective values.

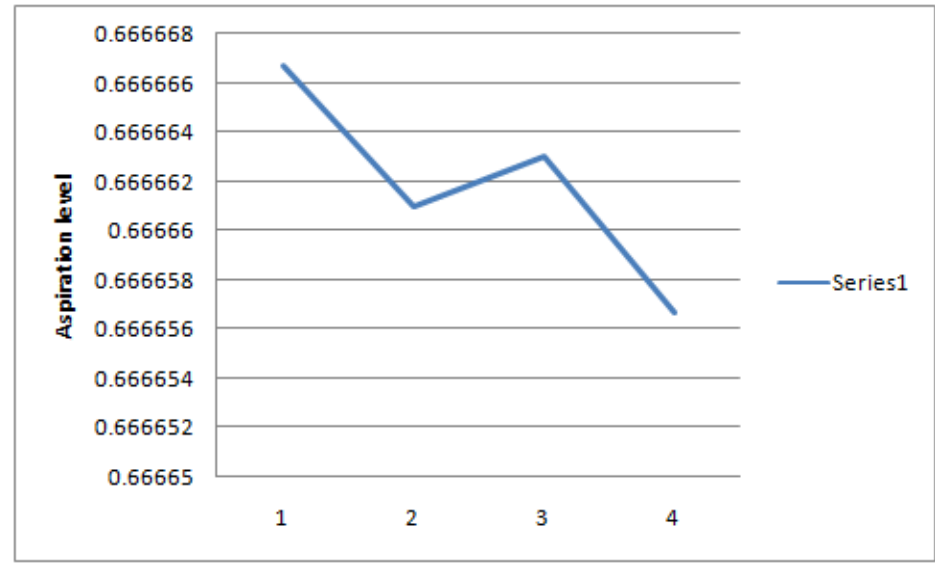

Figure 12. Level of satisfaction.

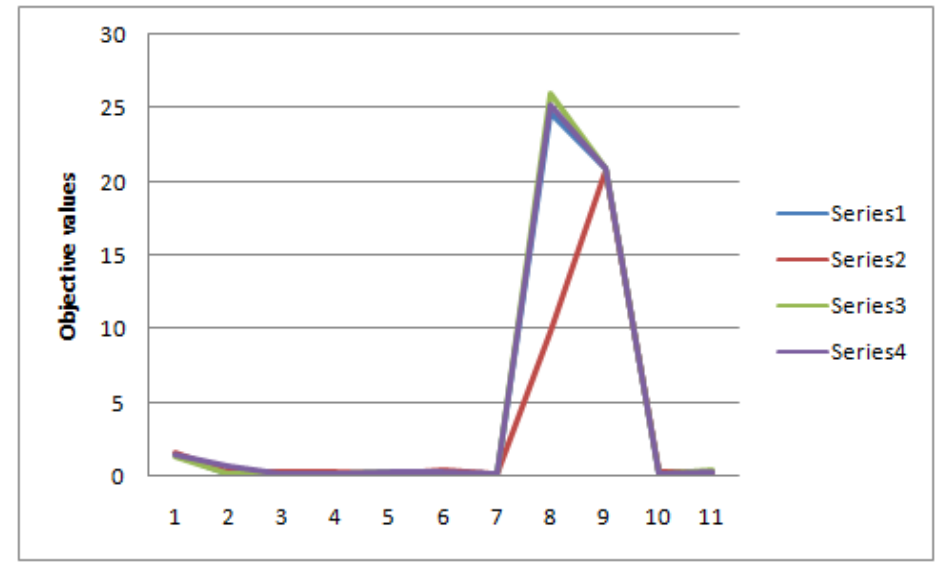

Figure 13. Objective values. 


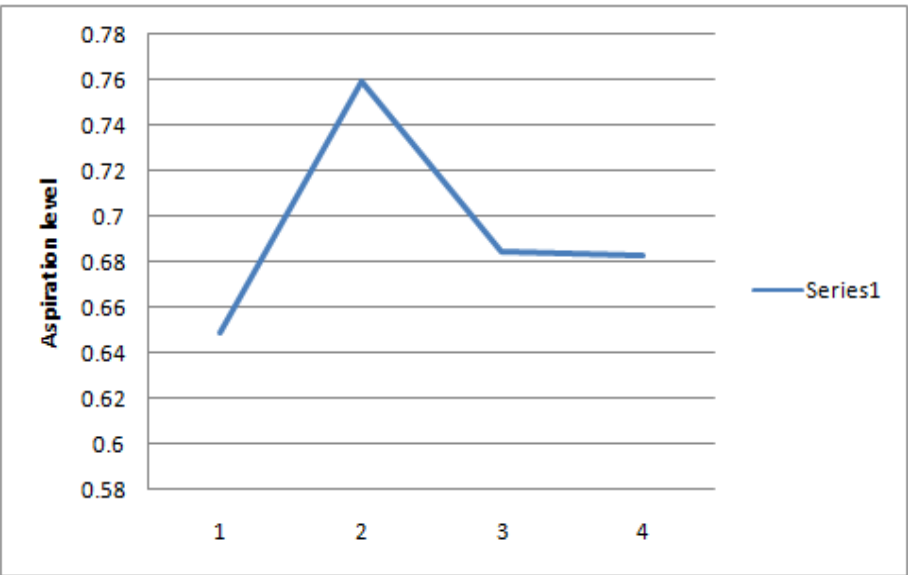

Figure 14. Level of satisfaction.
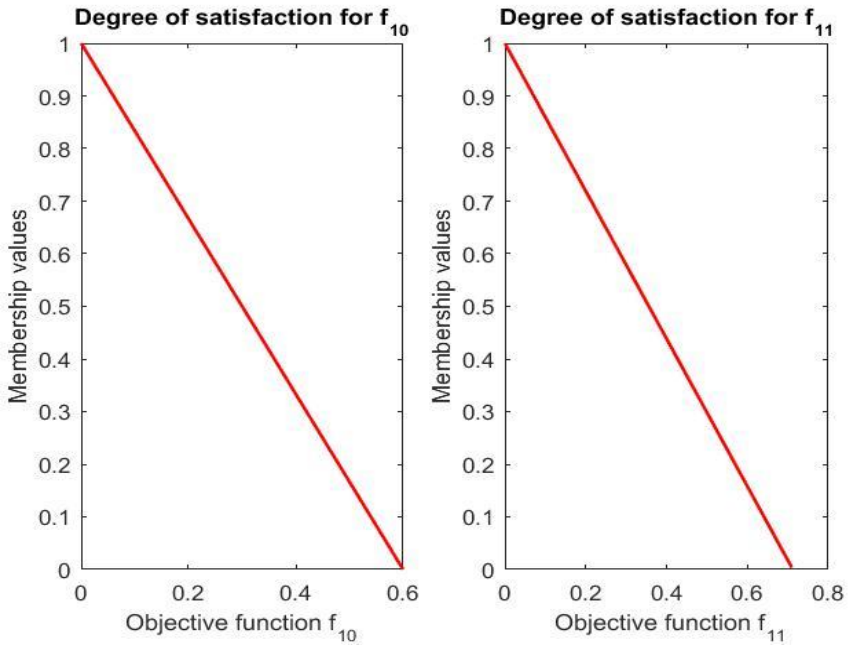

Figure 15. Linear membership function.

To study the sensitivity analysis of objective functions corresponds to uncertain constraints in OVM and DOCM, we carried out another complimentary test varying the confidence levels for two cases $\alpha_{\mathrm{t}}$. The first case represents $C_{1}:(\alpha=0.9)$ and the second case represents $C_{1}:(\alpha=0.1)$ in the objective functions of the OVM model. The sensitivity analysis Of the OVM model is done by changing the value of one confidence level of step size 0.1 in the range [0:1;0:9] and keeping the other confidence levels fixed as 0.9 for two cases $\mathrm{C} 1$ and $\mathrm{C} 2$. For instance, when we test the sensitivity of $\alpha$ in the range $[0: 1 ; 0: 9]$ for the first case $\mathrm{C} 1$, the values of other confidence levels are taken as 0.9 , i.e. $\alpha=0.1$. Since variating the values of the confidence levels will lead us to different models of OVM, we can obtain their solutions using the same methodology of fuzzy programming technique with linear and exponential membership functions. The results of the OVM model for these two cases $\mathrm{C} 1$ and $\mathrm{C} 2$ are shown in tables from Table 7 to Table 8 . Tables 7 to 8 indicate that the objective function values are decreasing concerning the tested confidence levels $\alpha$.in the range $[0: 1 ; 0: 9]$. 

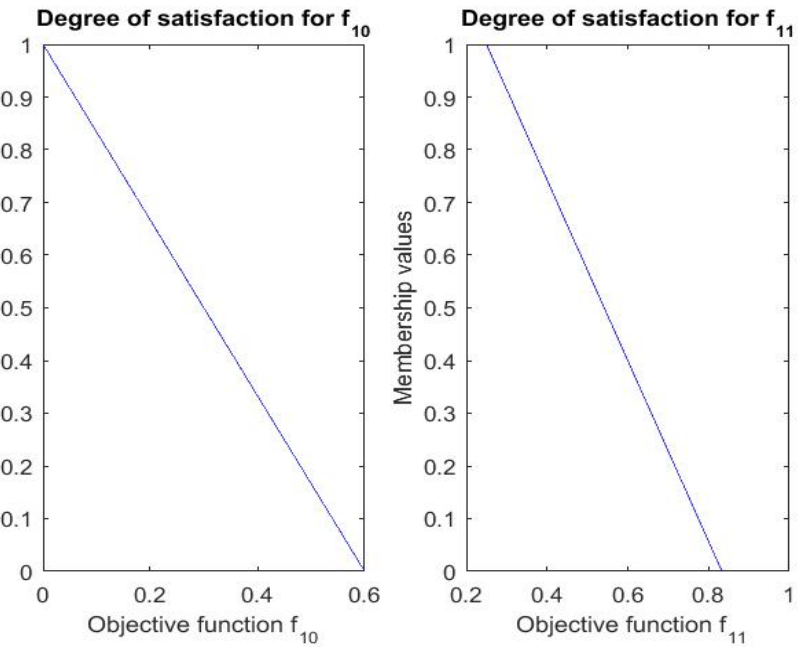

Figure 16. Exponential membership function.

Table 9. Objective values for distict membership functions for DOCM.

\begin{tabular}{|c|c|c|c|c|}
\hline $\begin{array}{c}\text { Objective } \\
\text { values }\end{array}$ & $\begin{array}{c}\text { Linear } \\
\text { Membership } \\
\text { function }\end{array}$ & $\begin{array}{c}s 1=s 2=s 3=s 4= \\
s 6, s 5=0.00001 \\
s 7=0.000005 \\
s 8=0.00005=s 9 \\
s 10=0.000001=s 11\end{array}$ & $\begin{array}{c}s 1=0.000009=s 2 \\
s 3=0.000005=s 4 \\
s 5=0.0005 \\
s 6=0.000009 \\
s 7=0.000001 \\
s 8=0.000005=s 9=s 10=s 11\end{array}$ & 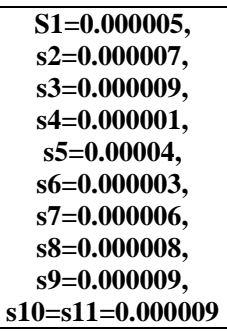 \\
\hline$\lambda$ & 0.6486486 & 0.7590283 & 0.6845515 & 0.6824485 \\
\hline Y1 & 0.008108108 & 0.009487945 & 0.008556901 & 0.008283923 \\
\hline F1 & 1.427027 & 1.641414 & 1.35199 & 1.449687 \\
\hline $\mathrm{F} 2$ & 0.1945946 & 0.2846383 & 0.2053656 & 0.7455531 \\
\hline F3 & 0.1945946 & 0.3036142 & 0.2053656 & 0.1988142 \\
\hline $\mathrm{F} 4$ & 0.1702703 & 0.3131022 & 0.1796949 & 0.2485177 \\
\hline F5 & 0.3648649 & 0.2277107 & 0.3337192 & 0.29822 \\
\hline F6 & 0.3243243 & 0.3984937 & 0.2395932 & 0.3065052 \\
\hline F7 & 0.1864865 & 0.1992468 & 0.1968087 & 0.1988144 \\
\hline F8 & 24.62432 & 9.857975 & 25.99587 & 25.19141 \\
\hline F9 & 20.85405 & 20.82922 & 20.84598 & 20.85089 \\
\hline F10 & 0.2108108 & 0.3131022 & 0.1796949 & 0.195302 \\
\hline F11 & 0.2675676 & 0.3890057 & 0.3765037 & 0.3644926 \\
\hline \multicolumn{5}{|c|}{ Courses assigned to faculties. } \\
\hline Fac-I & 11,13 & 11,13 & 11,16 & 11,16 \\
\hline Fac-II & $09,14,18$ & $09,14,18$ & 14,18 & 14,18 \\
\hline Fac-III & $03,15,16$ & $03,15,16$ & $03,08,12$ & $03,08,12$ \\
\hline Fac-IV & $04,05,10,17$ & $04,05,10,17$ & $01,05,07,15$ & $01,05,07,15$ \\
\hline Fac-V & $01,02,07,12$ & $01,02,07,12$ & $04,06,09$ & $04,06,09$ \\
\hline Fac-VI & 06,08 & 06,08 & $02,10,13,17$ & $02,10,13,17$ \\
\hline
\end{tabular}




\section{Conclusions}

In this paper, we have developed an uncertain mode for University course scheduling. The proposed uncertain model was transformed into deterministic mathematical models by using three different ranking criteria. All these models are multiple objectives models, which have been provided an optimal solution using the fuzzy programming approach. We have incorporated the preferences of faculties, administrators, and students in this proposed model. To satisfy student preferences, which are computed based on feedback analysis and result analysis. Due to insufficient data or data may available but not observing pattern, results in uncertain in nature of feedback and result parameters. Applied technique provided various alternating allocations by varying shape parameters. Many allocations are available with decision-makers with various degrees of satisfaction. Out of obtained allocations, whichever is suitable for the situation must be implemented.

\section{Conflict of Interest}

The authors confirm that there is no conflict of interest to declare for this publication.

\section{Acknowledgments}

This research did not receive any specific grant from funding agencies in the public, commercial, or not-for-profit sectors. The authors would like to thank the editor and anonymous reviewers for their comments that help improve the quality of this work.

\section{References}

Abdelhalim, E.A., \& El Khayat, G.A. (2016). A utilization-based genetic algorithm for solving the university timetabling problem (UGA). Alexandria Engineering Journal, 55(2), 1395-1409.

Al-Betar, M.A., Khader, A.T., \& Zaman, M. (2012). University course timetabling using a hybrid harmony search metaheuristic algorithm. IEEE Transactions on Systems, Man, and Cybernetics, Part C (Applications and Reviews), 42(5), 664-681.

Badri, M.A. (1996). A two-stage multiobjective scheduling model for [faculty-course-time] assignments. European Journal of Operational Research, 94(1), 16-28.

Badri, M.A., Davis, D.L., Davis, D.F., \& Hollingsworth, J. (1998). A multi-objective course scheduling model: Combining faculty preferences for courses and times. Computers \& Operations Research, 25(4), 303-316.

Bai, R., Burke, E.K., Kendall, G., \& McCullum, B. (2006). A simulated annealing hyper-heuristic for university course timetabling problem. Abstract) PATAT, 6 .

Bakır, M.A., \& Aksop, C. (2008). A 0-1 integer programming approach to a university timetabling problem. Hacettepe Journal of Mathematics and Statistics, 37(1), 41-55.

Bhoi, S.B., \& Dhodiya, J.M. (2020). Multi-objective faculty course timeslot assignment problem with resultand feedback-based preferences. In Conference proceeding Ambient Communications and Computer Systems (pp. 105-119). Springer, Singapore.

Costa, D. (1994). A tabu search algorithm for computing an operational timetable. European Journal of Operational Research, 76(1), 98-110.

Csima, J., \& Gotlieb, C.C (1964). Tests on a computer method for constructing school timetables. Communications of the ACM, 7(3), 160-163.

Daskalaki, S., \& Birbas, T. (2005). Efficient solutions for a university timetabling problem through integer programming. European Journal of Operational Research, 160(1), 106-120. 
Gunawan, A., Ng, K.M., \& Poh, K.L. (2012). A hybridized Lagrangian relaxation and simulated annealing method for the course timetabling problem. Computers \& Operations Research, 39(12), 3074-3088.

Hertz, A. (1991). Tabu search for large scale timetabling problems. European Journal of Operational Research, 54(1), 39-47.

Liu, D.B. (2007). Uncertainty theory. In: Liu, B. (ed) Uncertainty theory. Springer, Berlin, pp. 205-234.

Liu, B. (2009). Some research problems in uncertainty theory. Journal of Uncertain Systems, 3(1), 3-10.

Liu, B., \& Chen, X. (2015). Uncertain multiobjective programming and uncertain goal programming. Journal of Uncertainty Analysis and Applications, 3(1), 10. https://doi.org/10.1186/s40467-015-0036-6.

Liu, B., \& Liu, B. (2009). Theory and practice of uncertain programming (Vol. 239). Springer, Berlin, Heidelberg.

Najdpour, N., \& Feizi-Derakhshi, M.R. (2010). A two-phase evolutionary algorithm for the university course timetabling problem. In 2010 2nd International Conference on Software Technology and Engineering (Vol. 2, pp. 266-271). IEEE. San Juan, PR, USA.

Schniederjans, M.J., \& Kim, G.C. (1987). A goal programming model to optimize departmental preference in course assignments. Computers \& Operations Research, 14(2), 87-96.

Zimmermann, H.J. (1978). Fuzzy programming and linear programming with several objective functions. Fuzzy Sets and Systems, 1(1), 45-55. 